\title{
The Exploration and Construction of Teaching Team of Electronic Technology Course
}

\author{
Cheng Hong-li \\ College of Communication \& Information Engineering, \\ Xi'an University of Science \& Technology, Xi'an, China \\ Email: chhl@xust.edu.cn
}

Key words: electronic technology course; teaching team; teaching reformation;

\begin{abstract}
Electronic Technology Course as Electricity specialty basic course, its teaching effect directly impacts on student to study subsequent specialized courses and to master professional skills. In order to improve the teaching quality of the course, the formation and development of teaching team becomes imperative reform issues in colleges and universities. The necessity about on construction of electricity teaching team and the problems in building process are discussed in this paper, and some views on how to form the teaching team are put.
\end{abstract}

\section{Introductions}

Electronic technology is an important professional basic course of electricity specialty student. Teaching effectiveness of the course directly affects the students follow courses of study and professional skills to master. In order to improve the teaching quality of the course, the group in support of the school has always been carried out under the reform of teaching methods and research. However, in order to meet the cultivating high quality talents, and needs professional development under the new situation, we must find more effective teaching mode, teaching contents and teaching methods. This is a systematic project, we can not rely on a single or a few teachers to complete, building of teaching team and work effectively become imperative issues ${ }^{[1]}$. About how to build electronic course teaching team, the teachers in teaching team how to collaborate with each other and to improve their teaching level, and how to better train students' creative and practical ability in the case of hours crunch have become an urgent problem in our group .

\section{How to form teaching team}

Teaching work is the main line in teaching team, and to develop specialty, to reform course, to research teaching are important issues. The team is organized by teachers teaching, academic leaders, senior professional and technical positions teachers. Teaching team is a collective, teachers in the collective can complete teaching and research work independently, but must share resources and coordinate each other to get development of mutual cooperation, a team is formed in the work process. The team needs to have the following characters:

1) Need a clear goal of courses construction

To form a teaching team must first have a clear course construction goal, and it should be to build course of electronic technology, to build teaching materials, to build practical aspects of building as the goal. Electronic technology course is an important basic curriculum, to have many course contents and more practice, including: low-frequency electronic circuits, digital electronics technology, power electronics, high-frequency electronic circuits, EDA technology, various experimental course and curriculum design, a large number of course hours, wide coverage. Involving more projects and heavy task, inputs of both funding and time required are much, the teaching team members must clear their goal of building to improve the construction efficiency by collaborating with each other.

2) Need a clear orientation of teaching reformation 
Teaching team must actively carry out reformation and research of teaching methods and means, in order to cultivate high quality and creative talents as the goal ${ }^{[2]}$, to change completely the teaching mode with valuing the classroom theory teaching and underrating practice ability train, truly hands grasping. So, we must carry out a comprehensive exploration of the rational design of classroom teaching content and practice, and the corresponding teaching methods. To increase self-study time in order to improve students' motivation of studying. This requires teachers of the team to continuously improve their level of expertise and research ability in practice, to better fulfill students' thinking and practice skills in a limited class time, to solve effectively the difficulty of teaching courses by changing the abstract to the concrete.

3) Need reasonable teaching echelon

A reasonable echelon is the basis of formation and construction of teaching team, in order to play the role of teaching team, we need to further optimize the structure of teachers. In recent years, we have already introduced three young doctors, to make the team get new blood, to increase the vitality of our teaching team. Our teaching team has three professors, four associate professors, ten lecturers, including six doctors. Members of the teaching team are a reasonable echelon in age, education and other aspects of the job title. In future, the goal of building is to introduce some senior professionals as extracurricular instructor, and joint some ventures to create practice bases. We will train young experimental instructor to strengthen the training of practical aspects in school. In same time, we will enhance teachers' teaching level and technical titles.

\section{Meaning of teaching team construction}

Teaching quality is the lifeline of a school, teaching is the key content of undergraduate education, to build teaching team can further improve the quality of teaching. Teaching team building is mainly to build teachers' contingent, to optimize the structure of teachers, to improve teaching content, to improve teaching methods, to strengthen the exchange of teaching and research, to develop and share of teaching resources, to improve the overall level of education and training of personnel ${ }^{[3]}$. Specific significances are the following aspects:

1) Help to improve the overall quality of teachers

In the teaching team building, it can give full play to the leading role of academic leaders who can guide the team members, especially young teacher to find the direction of scientific research and support them to continue their studies, to pursue a degree for improving teaching and research capabilities. In the team event, we can get the exchange to carry out teaching and research experience in order to realize to combine with old, middle and young, and to continuously improve the team overall standard of teaching and practical research capacity, to promote the quality of overall teachers.

2) Help to reform teaching methods and teaching content

Teaching team building is to promote the teaching reform as the main task. Because members of the teaching team are to work in the first line of classroom teaching, to practice teaching methods and reformation of teaching content, so in practical teaching, they can use the most effective teaching methods and the latest teaching achievements, but also can make reasonable adjustments in due course to further improve teaching methods, so that students can get more new knowledge and practical skills to promote development in overall aspect.

3) Help students to improve ability of practice and innovation

Improving practice and innovation ability is the ultimate goal of teaching team construction, but also to enhance the quality of undergraduate teaching, and to be the base of training high-quality innovative talents. Teaching team can be combined with scientific research object and research achievement to guide students to get practical and innovative ability ${ }^{[4]}$. By solving practical problems, students can improve explore interests and capability to meet the teaching purposes of combination theory and practice, to better meet the needs of science, and technology development and high-tech talent. 


\section{The main work of teaching team building}

Electronics teaching team is one of basic course teaching team that our school first set up, regardless of the hardware environment or the connotation construction there is an urgent need in improving content. It includes the main work in the following areas:

1) Unite thinking and raise awareness

We must first clear direction and a body-building approach about building teaching team, according to the teaching content and teaching objectives of electronic technology courses, we set up a teaching team in line with the teaching requirements and professional development. Electronic technology course is the school's electrical class professional basic courses, involving a wide range of different specialized subjects, different teaching arrangements, different teaching requirements, teachers in teaching team have so great class time likely to conflict with research time. Therefore, teachers must firmly establish the "undergraduate teaching center, teaching quality as the fundamental" thinking. Specifically in several stages: first, full mobilization, to make team members to actively participate in the construction, to discuss the contents of the team's activities, to formulate building goals, to mobilize the initiative and enthusiasm to participate in the activities; secondly, to create good atmosphere of team building, team members can well cooperate with each other, work smoothly. Finally, to establish growth faith in the construction, to make each member understand that team building is an enduring work, it needs a multi-faceted learning exchange, and to constantly sum up lessons learned to improve their work.

2) Develop and enhance team spirit

Team sprit is that team members can collaborate and support to get the goal of team building and common interests, look team jobs as their duty to work hard together to improve the teaching quality of dedication. Team sprit is spirit and the quality of an excellent teaching team, training and promotion of team sprit is important work to team building. Specific measures include:

(1)Form a unified values.

Under the new situation multiparty conflict of values, so every member of the team must have always been convinced that teaching is always innate responsibility for a school, teaching and educating are the bounden duty of every teacher, teachers must identify with their career. Values will be discussed in team activities widely, to eliminate negative factors, to improve recognizing, and to enhance emotional communication between team members, to form the same values, to improve the work motivation of the team members.

(2)Target incentive.

The current teacher evaluation system led to many teachers to underrate university teaching and to pay more attention on scientific research, in this case, school, college, and the team must establish an effective incentive policy. Motivational content includes not only material incentives, such as to combine the situation of teachers accomplishing their goals in the teaching team with their performance rewards, but also for spiritual encouragement, such as at the time of assessing outstanding teachers, teaching teachers and job classification, they can get more opportunity.

(3) Establish a competitive mechanism.

Team building is a systematic project, requires all members to work together to complete. In the construction process, project manager must implement the tasks to each member and assess phased the implementation of task, at the same time establish exiting policy for members, teachers who do not conscientiously perform their duties can be cleared out of the teaching team. In addition, outstanding teachers can be actively introduced to join the teaching team ${ }^{[5]}$.

3) Construct hardware facilities

Electronics Course includes more basic course, of which there are simulation environment to apply and experiment platform to build. Because courses cover wide professional and many students, at present, due to condition constraints, many advanced teaching methods can not be used, and the experimental conditions can not meet students' practical needs. Look teaching team building as an opportunity to improve the teaching and laboratory facilities simultaneously, and to improve the working conditions of team teachers, to lay the foundation for cultivating high quality personnel. 


\section{Difficulties existing in the teaching team building}

Teaching team still in the initial stage of exploration, there are some difficulties in the construction process, mainly the following aspects:

\section{1) Lack of experience}

Teaching team building is the new education reform project at the undertaken situation, there is no ready-made experience to follow, the problem of what in the development of building objectives and evaluation policy is or not rational and scientific can be exist. We need to constantly adjust and improve in exploration so that work efficiency can be reduced.

2) Have difficult to introduce high-level personnel

Excellent members is the key for a team, due to historical reasons, this team still lacks some high level teachers as core of team, there are difficulties in introducing leaders who teach and research on double shoulder. The current efforts at introduction of talents are not big enough, hope school to provide more policy about introduction of talents to attract talented people to join.

3) Shortage of construction funds

Connotation and hardware construction in Team Building process are inseparable from financial support. To improve the hardware facilities needs more money to be invested. At present, we must first realize the popularity of multimedia teaching, to set up simulation platform, a larger opening of laboratory, in order to meet the growing needs of the students' after-school practice. AT the same time, investment funds also need to make instructional videos and online courses, to improve teaching methods.

\section{Conclusions}

Teaching team building can not only improve the quality of teaching, but also promote the development of all aspects of teachers, the most important thing is to unite the collective strength and wisdom to better accomplish the goal of cultivating high quality talents. To form excellent teaching team has been urgent needs for a school to enhance the competitiveness.

\section{Acknowledgements}

This paper is supported by the project of education reforming of Xian University of Science and Technology (2010513001)

\section{References}

[1] Fang Yu, Chen Yashao, Hu Daodao etc. Building of High Level teaching Team and Raising teaching Quality of Course [J]. China University Teaching .2012,01:49-52.

[2] Tian Ming, Meng Jun. Research on Building of Teaching Teams and Teaching \& Researching Section[J]. Journal of Inner Mongolia University for Nationalities (Social Sciences), 2011,05:106-109.

[3] Li Jiang lin. Thoughts on teaching team construction in higher school[J]. Journal of Hubei Normal University (Philosophy and Social Science), 2010,01:138-140.

[4] Jiang lin, Hu zhigang, Yang liu. On the Method of Competency Assessment and Continuous Improvement of Teaching Team for Training Outstanding Engineers' Cultivation[J]. Research in Higher Education of Engineering, 2012,06: 31-37.

[5] Huang yufei. Assessment and Management Research of Teaching Team in higher School[J]. China University Teaching, 2009,02:70-72. 